\title{
Traditional Drying Techniques for Fruits and Vegetables Losses Alleviation in Sub-Saharan Africa
}

\author{
${ }^{1}$ Rwubatse, Bernard, ${ }^{2}$ Akubor, Peter Issah and ${ }^{3}$ Mugabo, Emmanuel \\ ${ }^{1,2}$ Departement of Food Science \& Technology, University of Nigeria,Nsukka, Nigeria \\ 3. Departement of Food Science \& Nutrition, University of Ghana, Legon, Ghana
}

\begin{abstract}
World demand for sustainable food security, nutritional and healthy foods is increasing. The prevalence of food insecurity and undernourishment is $18.4 \%$ and $12 \%$ people worldwide, respectively, in 2011 - 2013 years. Highest percentage of postharvest losses, food insecurity and malnutrition - linked diseases are counted in sub Saharan african countries. The losses of fruits and vegetables were $44 \%$, roots and tubers $(20$ $\%)$ and cereals (19\%), oilseeds and pulses (3\%), meat (4\%) milk (8\%) fish and seafoods (2\%) in 2011. Fruits and vegetables are considered as the highest perishable of the plant source foods due to the highest amount of water they contain. Water content in fruits and vegetables range between $81 \%-88 \%$ and $90 \%-96 \%$, respectively. In 2011 year, the food loss in production was $23 \%$ in handling, $37 \%$ in storage and $7 \%$ in processing in sub Saharan Africa, while in the North african countries; the loss was $21 \%$ in handling and storage and 4\% in processing. In 2012 year, in 1.2 billion people without access to electricity, 590 million live in sub-Saharan Africa, mostly in rural areas. In 2.3 billion people who do not maximally benefit from electricity, 700 million are in sub Saharan Africa. Therefore, the use, adoption and up scaling of simple, economic, sustainable and effective postharvest techniques such as sun, passive solar and active solar drying are highly recommended for the contribution to fruits and vegetables preservation by ensuring the good nutrition and health of people in sub Sahara countries where electricity is a major obstacle.
\end{abstract}

Keywords: Fruits and Vegetables, Sub Saharan Africa, Traditional drying techniques

\section{Introduction}

The postharvest loss, especially of fruits and vegetables, is on the margins of undesirable amount for that there is lack and poor postharvest technology and management in sub Sahara african countries. [1] reported that roughly $1 / 3$ of the food production is lost or wasted every year, emitting the same amount of $\mathrm{CO}_{2}$ as 1.5 million cars. On a global scale that is about 750 billion U. S. Dollar in wastage a year. Thus, around one in eight people in the world are likely to have suffered from chronic hunger, not having enough food for an active and healthy life.

Drying which uses appropriate and effective techniques is one way amongst others to tackle postharvest losses in this developing part of Africa. [2] reported that the food losses in production, in handling, in storage and in processing in sub Saharan Africa were higher than those encountered in the North african countries. Perishable loss value in the sub Saharan african countries is higher than that of the North african countries from production, handling and storage chain to processing. The high loss in the sub Sahara african countries is caused mainly by poor technical and technological means for the preservation. According to [3], the big number of people with limited/without access to electricity is counted in sub-Saharan Africa. For those with limited access, they only use electricity for light during night, charging phones and computers, and for turning on televisions.

The alleviation of fruits and vegetables losses is clearly important since these foods provide people with many phytochemicals, essential vitamins and minerals such as vitamin A, vitamin C, fiber and potassium needed for leading healthier lives [4]. Fruits and vegetables constitute the main group of the super or functional foods. Dried fruits and vegetables are convenient for healthy eating and can bridge the gap between recommended intake of fruits and actual consumption. Dried fruits are nutritionally equivalent to fresh fruits, in smaller serving sizes, in the current dietary recommendations of various countries. Scientific evidence suggests that individuals who regularly consume generous amounts of dried fruits have lower rates of cardiovascular disease, obesity, various types of cancer, type-2 diabetes, and other chronic diseases [5]. Limited access to appropriate and postharvest techniques in sub Saharan part is one of the major causes of food losses. In some cases, crops geared for export in some countries are produced and handled correctly. However, most of the crops oriented for local consumption are generally of poor quality due to mishandling during harvesting, transport, storage, marketing and processing and due to lack of good infrastructure, such as roads, transport vehicles and insufficient know-how. 
Drying is one way which may be used to reduce and prevent fruits and vegetables losses amongst others such as organizing small farmers, diversifying, up scaling the production and marketing, investment in infrastructure and transportation, develop contract farming linkages between processors and farmers, marketing cooperatives and improved market facilities. The use of sun and solar is highly needed in sub Sahara countries where electricity is a major obstacle.

\section{Problem statement of the review}

In most sub Saharan countries, fruits and vegetables get spoilt very soon before they can be eaten and sold at the market and they cannot be stored for a long time, because basic storage knowledge and skills of the farmers and sellers are still so poor; preservation infrastructure is expensive and need electricity which is a major obstacle. The losses of fruits and vegetables become an environmental problem and ultimately lead to pollution. Many people are facing malnutrition and chronic diseases while these crops being lost are considered as important incubator of phytochemicals and nutrients such as fiber, vitamins and minerals.

\section{Impact of fruits and vegetables losses}

The issue of fruits and vegetables losses on one hand causes food insecurity in households and shortage of income to stakeholders such as farmers, processors, sellers and government. On the other hand, unconsumed fruits and vegetables also pose an environmental problem because of green house gases emissions from degradation of rejected foods. [1] indicated the amount of food loss and waste in 2010 was responsible for roughly 152.903 gigagram of greenhouse gas emissions (carbon dioxide equivalent). The more the surrounding place steadily gets destroyed, the more the human being life gets destroyed too. The high loss of fruits and vegetables being encountered on farm, at wholesale and household levels in developing countries pressures the already burden of nutrition - related diseases in families [6].

\section{Drying}

Drying is a technique used to reduce the availability water content in a material by heating or using chemical substances. The heat sources can be electric or global radiation. The sun is the central energy producer of the solar system. The small fraction of energy produced in the sun hits the Earth and makes life possible on the planet. The whole world energy need is based on the solar energy. All fossil fuel (oil, gas, charcoal) are converted solar energy. The radiation intensity of $6000{ }^{\circ} \mathrm{C}$ solar surface corresponds to 70,000 to $80,000 \mathrm{~kW} / \mathrm{m}^{2}$. The Earth receives a very small amount of this energy, Despites this, the incoming solar radiation energy in a year is some $200,000,000$ billion $\mathrm{kWh}$, this is more than 10,000 times the yearly energy need of the whole world [7]. The solar radiation intensity outside atmosphere is in average $1,360 \mathrm{~W} / \mathrm{m}^{2}$ (constant radiation). When the solar radiation penetrates through the atmosphere, some of the radiation is lost, therefore on clear sky sunny day in summer between 800 and $1,000 \mathrm{~W} / \mathrm{m}^{2}$ (global radiation) can be obtained on the ground [7]. The global radiation is composed of direct and diffuse radiations. The direct radiation comes from the direction of the sun. The diffuse radiation is created when the solar rays is scattered from the molecules and particles in the atmosphere into all directions, i.e. the radiations become unbeamed. The higher the amount of diffuse radiation is, the lower is the energy content of the global solar radiation. The duration of the sunshine and its intensity depend on the year, weather conditions and also on the geographical locations. The amount of global radiation on horizontal surface in a year may thus reach in sun belt regions over $2,200 \mathrm{kWh} / \mathrm{m}^{2}$ [7]. Therefore, the use of new drying techniques adapted to solar radiation could help reduce and prevent postharvest losses. Global radiation may also favor fast drying of highly perishable produce, such as fruits and vegetables in this region of Africa where solar radiation intensity is high.

The table below shows the monthly and annual averages of daily solar radiations $\left(\mathrm{kWh} / \mathrm{m}^{2}\right.$, day) for selected locations in sub Saharan Africa

Table 1. Averages of monthly and yearly values of global radiation on horizontal surface $\left(\mathrm{kWh} / \mathrm{m}^{2}\right)$

\begin{tabular}{|c|c|c|c|c|c|c|c|c|c|c|c|c|c|}
\hline Countries & January & February & March & April & May & June & July & August & September & October & November & December & Year \\
\hline Kampla, & 174 & 163.9 & 170.4 & 153.4 & 151.0 & 142.6 & 141.4 & 152.0 & 154.8 & 163.7 & 154.0 & 164.4 & 1885 \\
\hline \multicolumn{14}{|l|}{ Uganda } \\
\hline Moshi, & 179.8 & 169.4 & 179.8 & 162.0 & 148.8 & 148.8 & 147.2 & 187.6 & 169.5 & 182.9 & 165.0 & 178.2 & 2019 \\
\hline \multicolumn{14}{|l|}{ Tanzania } \\
\hline Harare, & 175.1 & 147.8 & 163.2 & 152.0 & 145.7 & 135.1 & 145.8 & 165.3 & 178.2 & 190.3 & 172.2 & 172.3 & 1943 \\
\hline Zimbabwe & & & & & & & & & & & & & \\
\hline
\end{tabular}


Source: Werner and Josef (2002)

\section{Types of traditional drying techniques}

The lack of appropriate preservation and storage systems cause considerable losses, thus reducing food chain supply significantly. The dent in food production can be ironed out by food conservation, e.g., by drying. Drying is a simple process of moisture removal from a product in order to reach the desirable moisture content. The removal of moisture prevents the growth and reproduction of microorganisms like bacteria, yeast and molds that cause decay and minimizes many of the moisture-mediated deteriorative reactions. In order to ensure the continuous fruits and vegetables supply for healthier growing population and to enable the farmers to produce high quality marketable products, efficient and at the same time affordable drying techniques are necessary. Studies have shown that even small and most simple oil-fired batch driers are not applicable to the most farmers, due to lack of capital and insufficient supply of energy for the operation of driers. The high temperature driers used in industrialized countries are found to be economically viable in developing countries only on large plantations or big commercial establishments. Therefore the introduction of low cost and locally manufactured solar driers offers promising alternative to reduce the tremendous fruits and vegetables losses. The opportunity to produce high quality marketable fruits and vegetables products seems to be a change to improve the economic situation of the farmers and sellers, and improve the health status of the consumers in sub Saharan Africa.

\subsection{Sun drying}

The traditional method of drying, known as sun drying or open-air drying, involves simply laying the product in the sun on mats, roofs or drying floors. Other methods include hanging the crop underneath a shelter, on trees and on racks in the field. Even though, this type of drying is frequently the most commercially used and viable technique to dry agricultural products in Africa, its full utilization by famers, sellers and processors of fruits and vegetables is still needed. During sun drying, heat is transferred by correction from surrounding air and by absorption or direct and diffuse solar radiation on the surface of crop. The converted heat is partly conducted to the interior increasing the temperature of the crop and partly used for effecting migration of the water and vapor from the interior to surface of the crop. The remaining amount of energy is used for evaporation of water at the surface or lost to ambient via convection or radiation. The evaporated water has to be removed from the surrounding of the crop by natural convection supported by wind forces [8]. Under ambient conditions, these processes continue until the vapor pressure of moisture held in the crop equals that of the atmosphere or reaches desirable equilibrium moisture content for safe storage.

\subsection{Solar drying}

Solar drying uses an enclosed unit, to keep the food safe from damage, birds, insects and unexpected rainfall. The food is dried using solar thermal energy in a cleaner and healthier way. The objective of solar drier is to supply the product with heat higher than that is available under ambient conditions, thereby increasing sufficiently the vapor pressure of the moisture held within the crop by decreasing significantly the relative humidity of drying air, and therefore increasing its moisture carrying capacity by ensuring sufficiently the low equilibrium moisture content for long conservation [9]. According to [10], the solar driers can be primary classified basing on the heating modes and the manner the solar heat is utilized.

1. passive solar energy driers (conventionally termed natural - circulation solar driers), and

2. active solar energy driers ( most of which are often termed hybrid solar driers).

\subsubsection{Passive solar driers}

They are generally of size appropriate on - farm use. They can be direct (tent and box drier) or indirect (cabinet drier). In these driers, the solar - heated air is circulated through the crop by buoyancy forces or as a result of wind pressure, acting singly or in combination.

\section{- Tent driers}

They are cheap, simple to build and consist of a frame of wood poles covered by plastic sheet. Black plastic must be used on the wall facing away from the sun. The crop to be dried is placed on a rack above the ground.

\section{- Box driers}

They consist of wooden box with hinged transparent lid. The inside is painted black and the food supported on a mesh tray above the drier floor. Air flows into through holes of the front and exits from vents at the top of the back wall.

\section{- Seesaw drier}


It has a rig and rectangular frame. The material to be dried is placed on a number of trays which have a wooden frame and a bottom mesh, which can be made of a variety of materials such as wire netting or old fish nets, bamboo lattice or any other material which allow a vertical air circulation and maximum evaporation. The bottom of improved seesaw drier is made of galvanized corrugated iron sheet reinforced crosswise by wooden planks and lengthwise by two wooden planks. Good thermal insulation can be provided by attaching insulation plates made of lignified wooden fiber, expanded polystyrene and various layers of corrugated cardboard etc. The upper surface of the bottom is painted black. The removable trays are placed on the top of corrugated iron bottom, either in a continuous row or with a space between them which results in a better heating of air above the blackened surface of corrugated iron bottom.

\section{- Cabinet solar drier}

The air is warmed during its flow through low pressure thermosyphonic solar collector and passes through air ducts into drying chamber and over drying trays containing the crops. The moist air is then discharged through air vents or chimney at the top of chamber. The cabinet is a large wooden or metal box. It should be insulated properly to minimize the heat losses and made durable. The crop is placed on the trays or shelves inside a drying chamber. If the chamber is transparent, the drier is termed integral - type or direct solar drier; if the chamber is opaque, the drier is termed distributed - type or indirect solar drier. Mixed mode drier combines the features of direct and indirect solar driers. Here the combined action of solar radiation incident direct to the crop to be dried and pre-heated solar air heater furnishes the necessary heat required for the drying process. The rotary wind ventilator made of corrugated van rotor can be placed on the top of a stack above a drying chamber. As the rotor spins in the wind, it expels the air from the ventilator stack. The air flows are critical factors in natural- circulation drying, thus they should be used especially in areas with relatively high average wind speed.

\subsubsection{Active solar driers}

They are also called forced convention or hybrid solar driers.

\section{- Natural convention driers with additional biomass back - up heater}

These driers help speed up the drying process of the crop by using back - up heating when the weather is poor and during night. Biomass, particularly fuel wood can be used as a source of energy. The drier is designed to operate with solar radiation as main source of energy. During the period of low or zero solar radiation, the back - up heater located below the drying chamber is used to supply hest energy. The combustion gases heat up the drum surface which in turn warms the air as it moves over the outer surfaces. The warm air rises into the drying chamber and dries up the crops.

\section{- Hybrid solar biomass drier}

The drying chamber has aluminum wire screen trays to hold products. The solar collector above matt black painted metal absorber sheet is attached to the backside of the drying chamber. The exhaust fan fixed in the chimney of the drying chamber forces the ambient air to pass through collector and rise up through crops being dried. The biomass gasifier stove assists drying whenever solar radiation is insuffient.

\section{Recommendations of the review}

The recommendations were focused on training, sensitizing and up scaling the use of effective, simple and cheap traditional drying techniques such as sun and solar drying to alleviate fruits and vegetables losses in sub Saharan Africa.

1. Synergy among food scientists, technologists, private and public institutions, governments, food related international organizations should sensitize farmers, sellers, livelihoods and processors and scale up the use of low cost and solar energy dependent traditional drying techniques to alleviate fruits and vegetables losses;

2. Consummation of dried fruits and vegetables should be maximized as these products lower rates of cardiovascular disease, obesity, various types of cancer, type-2 diabetes, and other chronic diseases [5];

3. Training and encouragement should mainstream females and young people about the of traditional drying because they are more involved in food preparation than males and old generation;

4. The awareness of the farmers, sellers, processors and consumers about the perishability of fruits and vegetables against the one of cereals, roots and tubers should be raised;

5. Establishment, development and sustainability of basic education in primary, secondary and post secondary schools on the nutritional and health potentials of dried fruits and vegetables should be done;

6. Public and private companies, states, local governments, researchers, policy makers should use social media to talk about the environmental hazard which can be caused by fruits and vegetables losses. 


\section{Outcomes of recommendations}

The practice of the recommendations would bring the benefits to the target group of farmers, households, cooperatives, companies, postharvest technology and management-devoted organizations, states and governments in four angles which are Think, Eat, Save and Income generation and market (TESI):

- Think (Choices): Farmers, consumers and food processors could think on choosing one favorable drying technique, more nutritious and healthier foods.

- Eat (Nutrition and Health): The use of the described driers could contribute to improve nutrition and health of consumers. Dried fruits and vegetables which are a source of fibers can be incorporated in drinks and foods during preparation. Therefore the digestion facilating power of fibers and therapeutic potential of phytochemicals associated with fruits fibers could be benefited by consumers. Phytochemicals (bioactive compounds) act as anti-oxidants, anti-cancer, bacteriostatic, anti-diabete, anti-ulcer, anti-inflammatory and anti-diarrhoe and anti- neurological disturbance, etc. [11].

- Save (Safe climate and food security): Drying could contribute to the reduction of losses fruits and vegetables and pollution problem in sub Saharan countries through the mitigation of the amount of greenhouse gases emissions in the atmosphere from degradation of rejected foods. The dried fruits and vegetables could be used in food processing plants such as bakery. The flour of dried fruits and vegetables could be used at the home level for the preparation of gari, soups and herbal tea, etc.

- Income generation and market: The practical utilization of traditional drying techniques could contribute to the increase in the total income for fruits and vegetables farmers, sellers and industries. Dried fruits and vegetables, lasting longer, would be available after harvesting season and are easily transported to the markets. That way, farmers would be receiving a regular income, which is needed for a secure and happy future.

\section{Conclusion}

The review suggested the alleviation of fruits and vegetables losses by using sun and solar drying techniques to fight food insecurity, improve nutrition and health of Saharan Africa population. These techniques are simple, cheap, appropriate and efficient. No need of electricity driers such as tent, box, seesaw, cabinet, passive and active solar were proposed in this review. Literates, lay, low, middle and high income people can use them. The global radiation drying dependent techniques would be advantageous in sub Saharan Africa due to very high radiation for the whole year in the region. The use, adoption, adaptation and widespread of these drying techniques would be the right choice due to many food companies, international organizations, research institutions, local governments and states are gradually investing in fruits and vegetables losses alleviation and management in a lot of african countries. Dried fruits and vegetables, lasting longer, would be available after harvesting season and are easily transported to the markets. That way, farmers would be receiving a regular income, which is needed for a secure and happy future. Consumers would get health promoting substances such as phytochemicals, vitamins, minerals and fibers for the body. These traditional drying techniques could contribute to the reduction of losses and pollution problem in sub Saharan countries through the mitigation of the amount of greenhouse gases emissions in the atmosphere.

\section{References}

[1] FAO, The state of food insecurity in the world. Food and Agriculture Organization of the United Nations, Rome, 2013

[2] FAO, Global food losses and food waste extent, causes and prevention. Food and Agriculture Organization of the United Nations, Rome, 2011

[3] World Energy outlook. International Energy Agency. 2012, 532.

[4] S. Gebhardt \& R. Thomas, Nutritive Value of Foods. U.S. Department of Agriculture, Agricultural Research Service, Home and Garden Bulletin, 2002

[5] Cesarettin, A., \& Fereidoon, S. (2013). "Dried Fruits: Phytochemicals and Health Effects". Wiley-Blackwell, 1-14

[6] K. Lisa \& C. Marita, Identification of appropriate postharvest technologies for improving market access and incomes for small horticultural farmers in sub-Saharan Africa and south Asia.WFL Grant Final Report to the Bill \& Melinda Gates Foundation. WF, 2010

[7] W. Werner and B. Josef, Solar drying. Establishement of production, sales and consulting infrastructure for solar thermal plants in Zimbabwe. Institute of sustainable technologies, Austria., 2002, 1 - 35

[8] M. Bux, W. Muhlbauer., K. Bauer and B. Kohler, Solar crop drying in developing countries, Berne, 2002

[9] O.V. Ekechukwu,1999). Review of solar - energy drying system II: an overview of solar drying dryingtechnology, energy conversion \& management, Pergamon, 40, 1999, 615 - 655.

[10] O.V. Ekechukwu, Experimental studies on integral - type natural - circulation solar - energy tropical crop driers, Ph.D. project. 1987

[11] R. H. Liu, Potential synergy of phytochemicals in cancer prevention: mechanism of action. Journal of Nutrition, 134 (12), $2004,479-485$. 